\title{
Aplicação de Cavacos de Titânio para Produção de Revestimentos Resistentes ao Desgaste
}

\author{
(Application of Titanium Machining Chips in Welding Consumables for Wear Resistant Hardfacing)
}

\author{
José Gedael Fagundes Júnior ${ }^{1}$, Rodolfo da Silva Manera², Ruís Camargo Tokimatsu ${ }^{3}$, Vicente Afonso Ventrella ${ }^{3}$,Juno Gallego ${ }^{3 *}$ \\ ${ }^{1} P P G E M$, UNESP - Ilha Solteira, Ilha Solteira, SP, Brasil, gedaelfagundes@gmail.com \\ ${ }^{2}$ Autocam Medical, Gerência de Produtos, Campinas/SP, Brasil \\ ${ }^{3}$ Universidade Estadual Paulista, UNESP - Ilha Solteira, Ilha Solteira, SP, Brasil, gallego@dem.feis.unesp.br*
}

\begin{abstract}
Resumo
Equipamentos usados nas usinas sucroalcooleiras e de extração mineral são submetidos a condições severas de desgaste abrasivo. Revestimentos duros são usualmente aplicados para reparar este tipo de dano, sendo bastante empregados consumiveis de soldagem contendo altos teores de cromo e carbono. No presente trabalho visa investigar a microestrutura de revestimentos duros formados com a fusão de cavacos de titânio puro ASTM F67 grau 4, material usado na fabricação de implantes odontológicos. Misturas com diferentes formadores de carbonetos ( $\mathrm{Fe}$ - $\mathrm{Cr}$ e $\mathrm{Fe}$ - $\mathrm{Nb}$ como aditivos) também foram testadas. Revestimentos feitos com duas camadas de cavacos "puros" (Ti), cavacos com $\mathrm{Fe}$ - $\mathrm{Cr}$ ( $\mathrm{Ti}$-Cr) e cavacos com $\mathrm{Fe}$ - $\mathrm{Nb}$ (Ti-Nb) foram depositadas sobre peças de aço-carbono por soldagem TIG/GTAW. A microestrutura das camadas foi observada com microscópio óptico e por microscópio eletrônico de varredura equipado com microanálise. A caracterização microestrutural revelou que a distribuição de carbonetos varia significativamente com a natureza química dos aditivos usados. A microanálise mostrou que houve a formação de carbonetos com composição química complexa no seio do metal de solda, cuja estequiometria foi determinada com análise por difração de raios-X. Carbonetos mistos do tipo MC e cementita foram identificados. Os resultados apresentados indicam que a aplicação de cavacos de titânio ASTM F67, como insumo para formação de carbonetos, pode contribuir para melhorar a resistência ao desgaste em comparação aos tradicionais revestimentos duros com carbonetos de cromo.
\end{abstract}

Palavras-chave: soldagem GTAW, revestimento duro, carbonetos, reciclagem de titânio, microestrutura, resistência ao desgaste.

Abstract: Equipments of the sugar-cane plants and mineral extraction are submitted to severe abrasive wear conditions. Welded hardfacing are usually applied to repair that kind of damage where commercial chromium/carbon-rich welding consumables have usually been employed. In the present work was investigated the microstructure of experimental hardfacings made by addition of residues (chips) collected from machining of ASTM F67 (unalloyed Ti, grade 4) alloy. Mixtures with different carbide-formers (Cr/Nb ferro-alloys) were also tested. Two layers of "pure" chips (Ti), chips plus $\mathrm{Fe}-\mathrm{Cr}$ (Ti-Cr), and chips plus Fe-Nb (Ti-Nb) were applied on low-carbon steel specimens by GTAW/TIG process. The microstructure of hardfacing layers was observed by optical and scanning electron microscopy (SEM) equipped with EDS microanalysis. The microstructural characterization has determined that carbide distributions change significantly with the chemical nature of the hardfacing. SEM observations coupled with EDS microanalysis have confirmed the formation of complex carbides within metal weld, whose stoichiometry was determined by X-rays diffraction (XRD) analysis. Mixed carbides MC-type and some cementite have been found. As a result it was suggested that using of ASTM F67 chips as carbide formers for composition of welding consumables can contribute to improve wear resistance of hardfacings, if compared with traditional chromium-based hardfacings.

Key-words: GTAW/TIG welding, hardfacing, carbides, titanium chips recycling, microstructure, wear resistance.

\section{Introdução}

As ligas de titânio ASTM F67 (Ti puro, grau 4) e ASTM F136 (liga Ti-6Al-4V) tiveram rápida e efetiva aceitação no mercado de próteses e implantes odontológicos devido às ótimas

Recebido em 05/05/2014, texto final em 25/09/2014. DOI: http://dx.doi.org/10.1590/0104-9224/SI1903.09 propriedades biomédicas, entre as quais se destacam a resistência à corrosão, biocompatibilidade, bioadesão e propriedades mecânicas similares aos tecidos ósseos [1]. Os implantes são fabricados em diversos formatos e tamanho, normalmente com diâmetro entre 3 a 5 milímetros e comprimento entre 15 a 20 milímetros. A produção seriada dessas peças com geometria complexa é feita pela usinagem de barras cilíndricas em máquinas com Comando Numérico Computadorizado (CNC). O volume de material removido (cavacos) é bastante significativo, sendo normalmente $40 \%$ do volume da peça ou superior em alguns casos. Ainda não há um mercado para este tipo de resíduo (cavaco) no Brasil, tornando o seu descarte bastante oneroso 
para as empresas do setor.

Revestimentos resistentes ao desgaste abrasivo são formados por camadas metálicas duras depositadas por soldagem, normalmente endurecidas por carbonetos de cromo. Os consumíveis usados na soldagem utilizam ferro-cromo com elevado teor de carbono em sua composição, tornando possível a formação dos carbonetos na poça de fusão. A maioria dos trabalhos científicos nesta área está relacionada à caracterização mecânica e estrutural de revestimentos duros contendo carbonetos de cromo [2-4]. As ligas ASTM F67 eASTM F136 são compostas por elementos químicos formadores de carbonetos, como o titânio e o vanádio, tornando tecnicamente possível a aplicação deste tipo de resíduo (cavacos) para produção de revestimentos duros. A adição de titânio e outros formadores de carbonetos na soldagem de revestimentos com alto teor de cromo e carbono foi investigada por diferentes pesquisadores [5-8]. O presente trabalho visa investigar a microestrutura de revestimentos duros experimentais, com ênfase na formação de carbonetos primários, onde cavacos da liga ASTM F 67 (Ti puro, grau 4) foram usados na fabricação de consumíveis para soldagem a arco com eletrodo de tungstênio e proteção gasosa (GTAW/TIG). A formação de carbonetos durante a soldagem de misturas de cavacos com ferro-cromo ou ferro-nióbio também foi avaliada.

\section{Materiais e Métodos}

Os cavacos do titânio ASTM F67 foram coletados e passaram por um processo de limpeza, para remoção de resíduos oriundos da usinagem. A Figura 1(a) ilustra o aspecto típico do material após esta etapa de limpeza. Para tornar possível a inserção do resíduo no interior de tubos de aço inoxidável austenítico AISI 304 cavacos foram triturados, Figura 1(b). O dispositivo utilizado para quebrar as longas espiras é apresentado na Figura 1(c) e foi acoplado a uma furadeira de coluna vertical, usada em baixa rotação (90 rpm). Ferro-cromo e ferro-nióbio em pó foram usados como aditivos, cujas composições químicas são indicadas na Tabela 1.

Para a formação de carbonetos foi necessário adicionar carbono aos cavacos e ao Fe-Nb. A Tabela 1 apresenta a composição química, em massa, dos insumos usados para a produção dos revestimentos, onde se constata que apenas o ferro-cromo contém carbono em quantidade suficiente para a formação de carbonetos. Considerando a estequiometria para carbonetos do tipo MC (cúbico) foi calculada a adição de 3 g de grafite em pó para $10 \mathrm{~g}$ de cavacos de titânio, sendo necessário apenas $1,2 \mathrm{~g}$ de grafite para $10 \mathrm{~g}$ de ferro-nióbio. As misturas em pó tiveram a adição de $2 \%$ em massa de silicato de sódio, composto usado como agente vitrificante.

As misturas foram umedecidas com pequena quantidade de água destilada para formar uma pasta fácil de ser introduzida nos tubos de aço inoxidável AISI 304, que tinham 4,0 mm de diâmetro externo com 0,25 mm de espessura de parede e $250 \mathrm{~mm}$ de comprimento. A mistura pastosa foi compactada no interior dos tubos com ajuda de uma haste metálica. Para a soldagem dos revestimentos foram produzidos três tipos de consumíveis: (i) varetas compostas por "cavacos puros", identificadas doravante por "Ti"; (ii) varetas com mistura de cavacos e Fe-Cr na proporção 1:1 em massa, identificadas por "Ti-Cr" e (iii) varetas com mistura de cavacos e Fe-Nb na proporção 1:1 em massa, identificadas por "Ti-Nb". Após a preparação as varetas foram armazenadas em estufa a $80^{\circ} \mathrm{C}$ por 24 horas, no mínimo, para sua completa desidratação.

Tabela 1. Composições químicas dos insumos utilizados (\% massa).

\begin{tabular}{|c|c|c|c|c|c|c|c|}
\hline & $\mathrm{Ti}$ & $\mathrm{Cr}$ & $\mathrm{Nb}$ & $\mathrm{C}$ & $\mathrm{Si}$ & $\mathrm{P}$ & $\mathrm{Fe}$ \\
\hline ASTM F67 & Bal. & - & - & 0,08 & - & - & 0,50 \\
\hline Fe-Cr & - & 55,2 & - & 7,70 & 3,50 & 0,03 & Bal. \\
\hline Fe-Nb & - & - & 64,7 & 0,09 & 2,70 & 0,20 & Bal. \\
\hline AISI 304 & - & 18,0 & - & 0,08 & 1,00 & 0,04 & Bal. \\
\hline
\end{tabular}

Nota: Bal. representa balanço em massa.

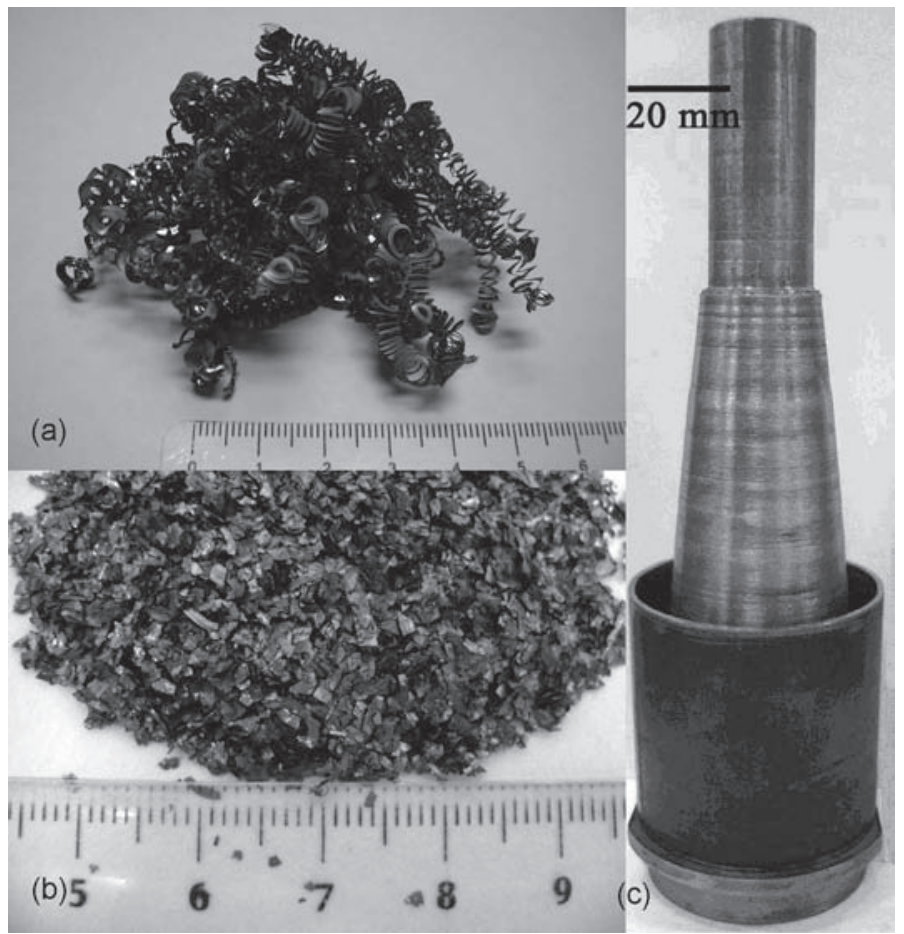

Figura 1. Aspecto dos cavacos da liga ASTM F67 antes (a) e depois (b) da trituração feita no dispositivo mostrado em (c).

Para a deposição dos revestimentos foram preparados corpos de prova, feitos com aço estrutural com baixo teor de carbono (ASTM A36), usinados com dimensões nominais $25 \times 9,5 \times 76$ mm. A fusão das varetas Ti, Ti-Cr e Ti-Nb empregou soldagem GTAW/TIG manual, de forma que as peças foram recobertas com 2 camadas compostas por cordões longitudinais ao comprimento do metal base. Durante a soldagem a corrente elétrica variou entre 150 a 160 ampères, sendo empregada polaridade direta com eletrodo EWTh-2 ( $\phi$ 2,4mm) negativo. Argônio puro foi usado para a proteção da poça de fusão, com uma vazão média de 10 litros por minuto. Após a soldagem, os revestimentos foram escovados e retificados de maneira cuidadosa a fim de remover o mínimo de material possível e garantir uma superfície plana e livre de impurezas, para a preparação metalográfica da 
superfície e realização de ensaios de dureza.

A seção transversal dos revestimentos duros foi preparada em amostras embutidas em resina de poliéster e as superfícies lixadas conforme procedimento metalográfico tradicional. $\mathrm{O}$ acabamento foi dado com polimento mecânico com alumina, nas granulometrias $1 \mu \mathrm{m}$ e $0,3 \mu \mathrm{m}$. $\mathrm{O}$ ataque metalográfico foi feito com um reagente composto por $5 \mathrm{~g}$ de cloreto de cobre, $100 \mathrm{ml}$ de ácido clorídrico, $100 \mathrm{ml}$ de etanol e $100 \mathrm{ml}$ de água destilada. A microestrutura foi examinada por microscopia ótica e microscopia eletrônica de varredura (MEV), sendo a microanálise feita por espectroscopia de energia dispersiva de elétrons (EDS).

A determinação das fases no revestimento foi realizada por difração de raios-X (DRX) usando um difratômetro equipado com tubo de cobre $\left(\mathrm{Cu} \mathrm{K} \mathrm{K}_{\alpha}=1,5405 \AA\right)$ e monocromador de grafite. A intensidade difratada pelas amostras foi registrada no intervalo entre 30 a $100^{\circ}$, varrida com velocidade de $2^{\circ}$ por minuto. A identificação das fases foi baseada nas fichas cristalográficas CIF, as quais foram consultadas no banco de dados do Inorganic Crystal Structure Database [9]. A fração volumétrica das fases identificadas não foi determinada. A variação da dureza nos revestimentos foi avaliada por medidas de dureza Vickers, sendo utilizada uma carga padrão de 30kgf durante 15 segundos [10]. Para estatística foram feitas, no mínimo, 10 medições por amostra. Os resultados foram tratados com um nível de significância de $95 \%$, sendo empregada a análise de variância (ANOVA) para avaliar as diferenças entre as medidas realizadas.

\section{Resultados e Discussão}

A tocha GTAW/TIG forneceu energia térmica concentrada na poça de fusão, na ordem de 4000 a 4250 joules por segundo. Esta energia foi suficiente para promover a fusão dos compostos usados na fabricação das varetas e diluir os elementos formadores de carbonetos no metal de solda fundido. As varetas usadas neste estudo - Ti (cavacos), Ti-Cr e Ti-Nb - apresentam diferentes teores de elementos formadores de carbonetos, como apresenta a Tabela 2. Nela não foi considerada a composição do tubo de aço inoxidável usado, mas considerando as composições químicas apresentadas na Tabela 1 presume-se que até $99 \%$ da massa das varetas Ti possa contribuir para a formação de carbonetos do tipo TiC. Analogamente, até $77,1 \%$ da massa das varetas $\mathrm{Ti}-\mathrm{Cr}$ poderia resultar na formação de carbonetos mistos (Ti,Cr)C no seio da poça de fusão durante a soldagem. Já esta proporção para as varetas $\mathrm{Ti}-\mathrm{Nb}$ seria $81,8 \%$ da massa adicionada poderiam originar carbonetos do tipo (Ti,Nb)C.

Tabela 2. Proporção nominal dos formadores de carboneto nas misturas usadas nas varetas produzidas.

\begin{tabular}{|c|c|c|c|c|}
\hline \multirow{2}{*}{ Vareta } & \multicolumn{4}{|c|}{ Elemento formador de carboneto (\% massa) } \\
\cline { 2 - 5 } & $\mathrm{Ti}$ & $\mathrm{Cr}$ & $\mathrm{Nb}$ & total \\
\hline $\mathrm{Ti}$ & 99,0 & - & - & 99,0 \\
\hline $\mathrm{Ti}-\mathrm{Cr}$ & 49,5 & 27,6 & - & 77,1 \\
\hline $\mathrm{Ti}-\mathrm{Nb}$ & 49,5 & - & 32,3 & 81,8 \\
\hline
\end{tabular}

A formação de diferentes quantidades mássicas de carbonetos, Tabela 2, e a variação da composição química dos carbonetos formados contribuíram para alterar a soldabilidade das varetas produzidas. A formação e a estabilidade química de compostos podem ser interpretadas por parâmetros termodinâmicos, como a variação da energia livre de Gibbs $\Delta G^{\circ}$ para a formação de carbonetos [11-13]. A relação de $\Delta \mathrm{G}^{\circ}$ com a temperatura pode servir como critério termodinâmico para estabelecer a ordem de formação dos carbonetos na poça de fusão [12]. Desta forma espera-se que a sequência para nucleação de carbonetos cúbicos "puros" a partir da soldagem GTAW/TIG das varetas seja TiC $\mathrm{NbC}-\mathrm{Cr}_{23} \mathrm{C}_{6}-\mathrm{Fe}_{3} \mathrm{C}$. A temperatura de fusão desses carbonetos decresce na mesma sequência sendo maior para o TiC (3340 K) e menor para a cementita (1498 K) [13]. Este último possui estrutura cristalina ortorrômbica e foi indicada apenas como referência.

Assim, a soldagem das varetas $\mathrm{Ti}$, com os mais altos teores de titânio, exigiu que a tocha GTAW/TIG se deslocasse com menor velocidade durante a soldagem manual. O efeito do superaquecimento causou maior empenamento e a formação de trincas no revestimento Ti. A mistura dos cavacos de titânio com os ferro-ligas nas varetas $\mathrm{Ti}-\mathrm{Cr}$ e $\mathrm{Ti}-\mathrm{Nb}$ contribuiu para formar carbonetos complexos, cuja formação demandou menor variação de energia livre. Assim, o ciclo térmico aplicado aos revestimentos $\mathrm{Ti}-\mathrm{Cr}$ e $\mathrm{Ti}-\mathrm{Nb}$ atenuou o superaquecimento do substrato usado, reduzindo os níveis de empenamento e trincamento. As adições de cromo e nióbio ao metal de solda também afetaram a dureza e a microestrutura dos revestimentos, como será visto adiante.

Aanálise por microscopia óptica mostrou que os revestimentos apresentam uma microestrutura preponderantemente composta por partículas de segunda fase envoltas pela matriz. Observandose as amostras na condição apenas polida percebe-se que há entre as partículas e a matriz uma significativa diferença de dureza, pois se formou um relevo característico onde as partículas (mais duras) sobressaiam do plano da matriz [14]. A Figura 2 apresenta exemplares típicos da precipitação observada nos revestimentos investigados, onde se percebe a variação na morfologia das partículas de segunda fase. Medidas de dureza Vickers sugerem que estas partículas sejam responsáveis pelo endurecimento da matriz, Figura 3, constituindo os carbonetos formados durante a soldagem GTAW/TIG dos revestimentos. ANOVA confirma que não há diferença significativa entre as durezas dos revestimentos Ti e Ti-Nb. O mesmo não acontece com a dureza da camada Ti$\mathrm{Cr}$, que é significativamente mais baixa que as outras.

A microscopia eletrônica de varredura constitui uma importante ferramenta para a observação de detalhes imperceptíveis ao microscópio óptico, combinando imagens com informação de natureza química. A Figura 4(a) apresenta a microestrutura dendrítica encontrada no revestimento Ti. Os carbonetos de titânio aparecem escuros no contraste composicional obtido por elétrons retroespalhados (BSE) [15]. Microanálises feitas por espectroscopia de energia dispersiva dos elétrons (EDS) confirmaram que o teor de titânio nos carbonetos variou entre 90 a $95 \%$ em massa (\%m), além da presença de ferro (3 a 4,5\%m) e cromo (1 a 2\%m). Os carbonetos de titânio 
encontrados no revestimento Ti apresentaram baixos teores de ferro e cromo, Figura 4(b), resultado que foi atribuído à maior disponibilidade e afinidade química entre o carbono e titânio em relação aos demais formadores de carbonetos [11]. Os bolsões interdendríticos mostram significativo empobrecimento de titânio, contendo no máximo $30 \% \mathrm{~m}$ do elemento. O principal elemento químico nestas regiões é o ferro, que variou entre 60 a $70 \%$ em massa.

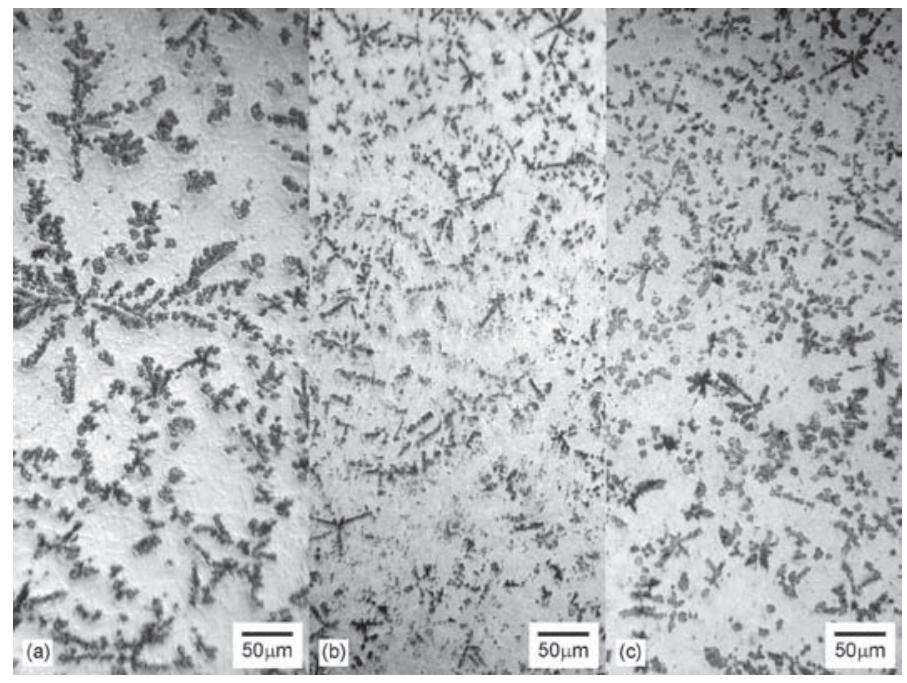

Figura 2. Micrografias ópticas mostrando partículas de segunda fase encontradas na seção normal dos revestimentos Ti (a), TiCr (b) e Ti-Nb (c). Aumento nominal: 100 vezes.

O revestimento Ti-Cr, Figura 5(a), apresentou microestrutura constituída por ramos dendríticos compostos por partículas com morfologia globular ou estelar. O contraste BSE escuro sugere que se tratam de partículas formadas com elementos químicos mais leves que a matriz ferrosa. De fato, a microanálise EDS dessas partículas indica que as mesmas sejam compostas em média por $45 \%$ de titânio, enquanto que o teor deste elemento na matriz ferrosa foi apenas $1 \%$. A dispersão das partículas foi bastante irregular, provavelmente favorecida pela diluição e

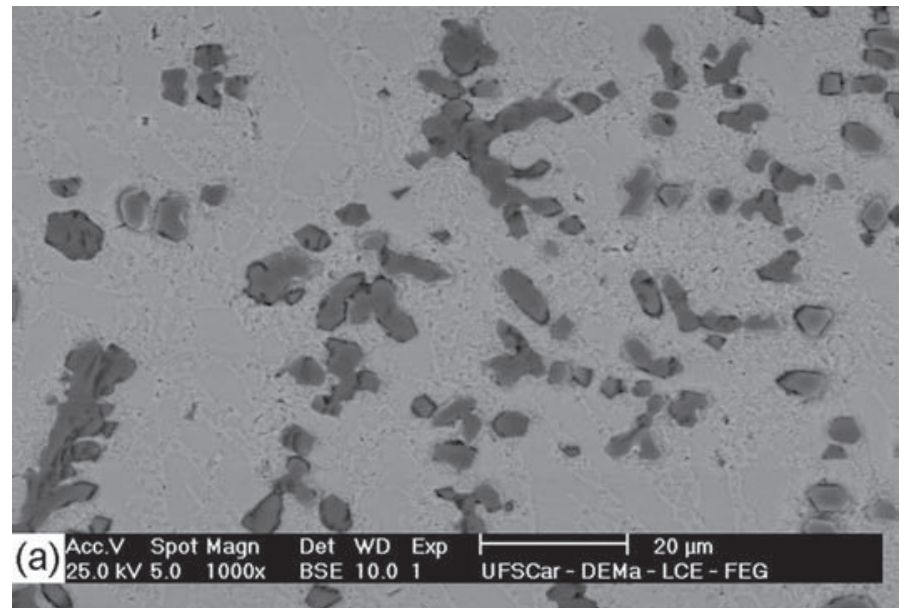

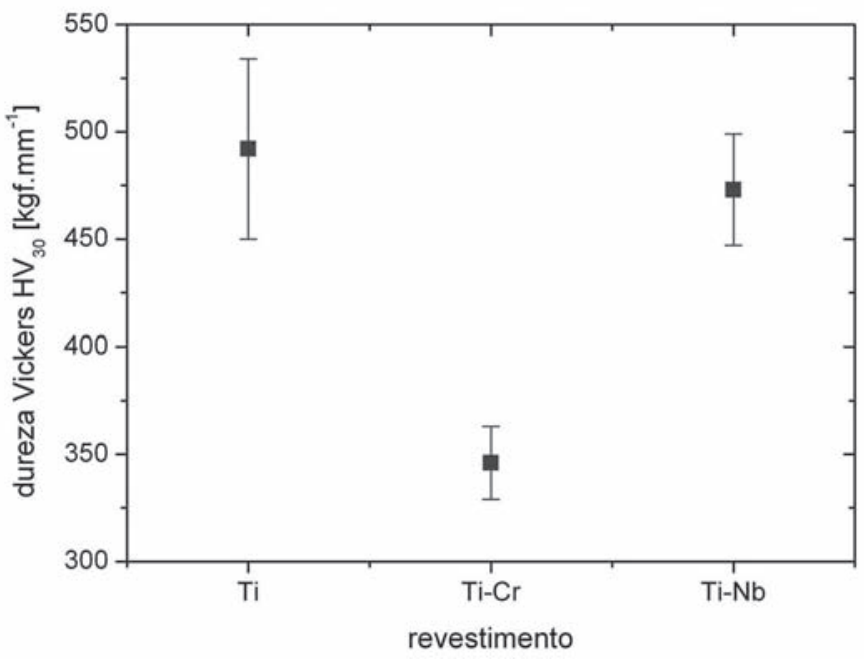

Figura 3. Variação da dureza Vickers nos revestimentos Ti, TiCr e Ti-Nb.

ciclo térmico conferidos durante a soldagem do revestimento. O cromo teve participação, entre 3 a 5\% em massa, na formação das partículas. Concentrações similares foram encontradas para o níquel e o silício. Entretanto, houve um aumento no teor de cromo, entre 5 a 10\% em massa, na composição química da matriz ferrítica. Para o níquel esta concentração chegou a 2\% em massa, concentração similar à encontrada no revestimento Ti. Esta variação de composição química é consistente com os resultados divulgados por Wu e colaboradores [16], onde camadas de carbonetos de cromo poderiam nuclear sobre os carbonetos de titânio primários formados em ferro fundido branco hipereutético.

A microestrutura do revestimento Ti-Nb está representada na Figura 6(a). Carbonetos com morfologia complexa foram observados, sendo notada a participação efetiva tanto do nióbio quanto do titânio na formação dos carbonetos primários. Estes elementos possuem forte afinidade química pelo carbono, maior que o cromo [11]. A microanálise EDS confirmou que o titânio e o nióbio apresentaram comportamento cooperativo na formação

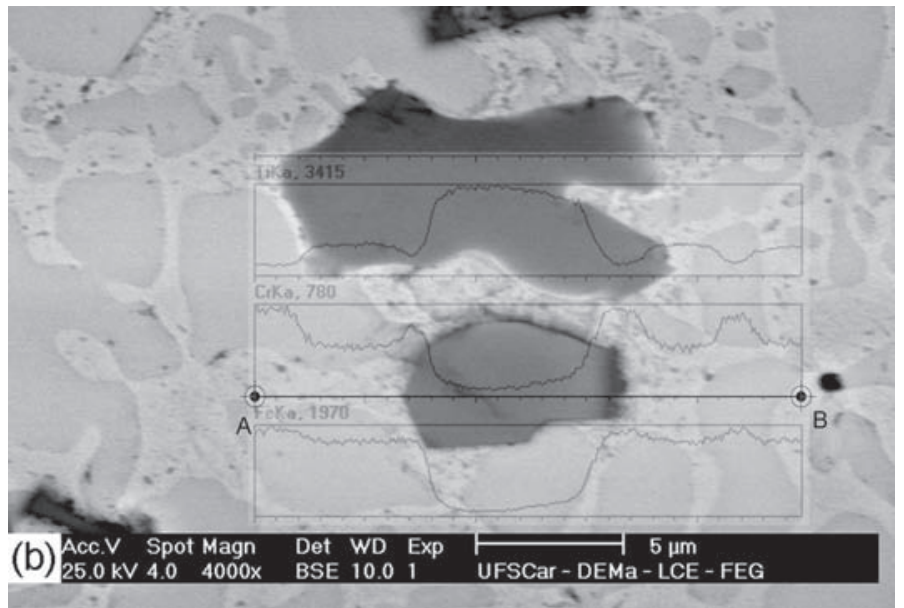

Figura 4. Micrografias MEV com contraste de elétrons retroespalhados (BSE) do revestimento Ti. Panorâmica de carbonetos em (a) e variação da composição química (EDS) entre os pontos A-B em (b). 

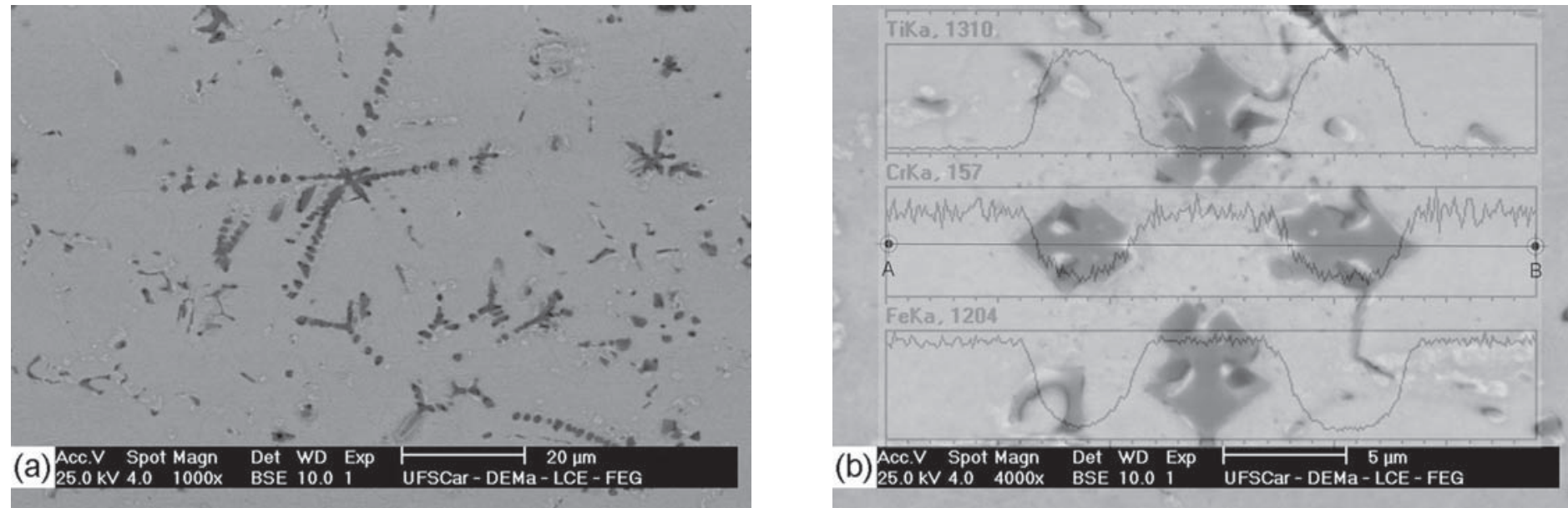

Figura 5. Micrografias MEV com contraste de elétrons retroespalhados (BSE) do revestimento Ti-Cr. Panorâmica de carbonetos em (a) e variação da composição química (EDS) entre os pontos A-B em (b).
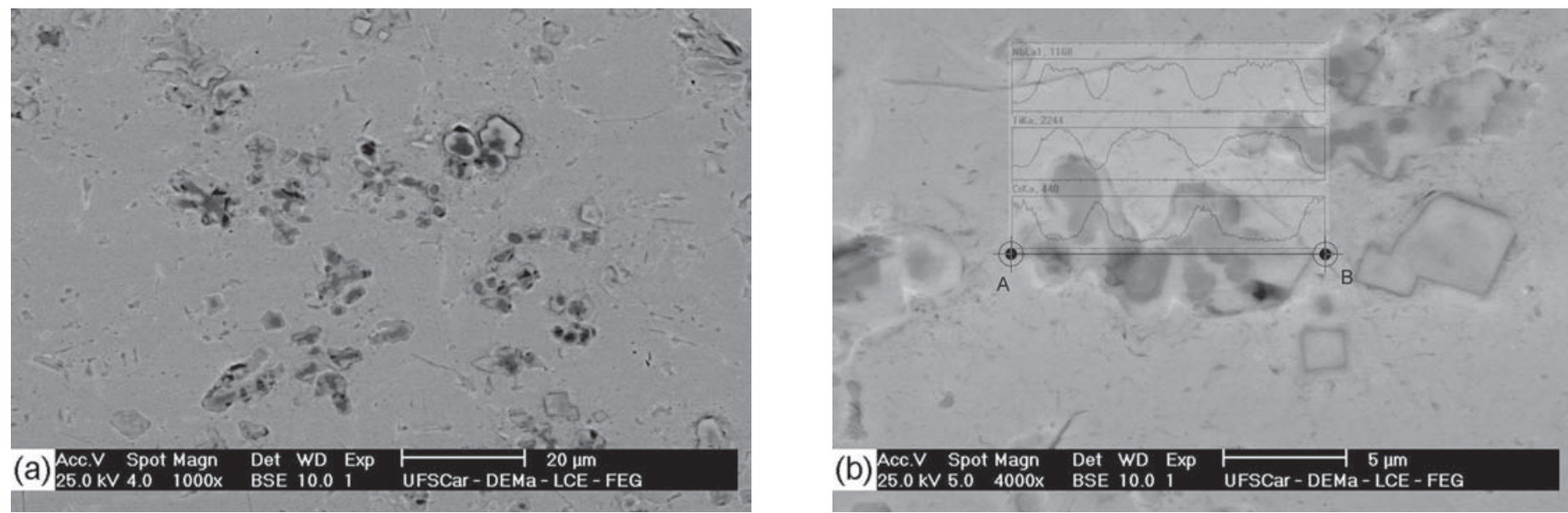

Figura 6. Micrografias MEV com contraste de elétrons retroespalhados (BSE) do revestimento Ti-Nb. Panorâmica de carbonetos em (a) e variação da composição química (EDS) entre os pontos A-B em (b).

dos carbonetos, restringindo a partição de carbono com o cromo e o ferro. Mesmo assim foi possível observar, Figura 6(b), gradientes de concentração dos elementos formadores de carbonetos no interior de uma mesma partícula. As regiões com contraste BSE mais escuro apresentaram menores concentrações de nióbio, aproximadamente $35 \%$ em massa, enquanto nas partículas que apresentaram aspecto mais claro e uniforme o teor de nióbio superou a $42 \%$ em massa. O teor de titânio nestas mesmas partículas oscilou entre 48 e 52\% em massa. Ferro (8 $10 \%)$, cromo (1-1,5\%) e silício (até $0,3 \%)$ também fazem parte da composição química (em massa) destes carbonetos. A matriz ferrítica nos revestimentos Ti-Nb é composta em massa por 85 a 90\% de ferro, de 8 a 12\% de cromo e de 2,5 a 3\% de titânio.

A caracterização por difração de raios-X (DRX) confirmou que a matriz ferrosa em todos os revestimentos era composta por ferrita com estrutura cúbica de corpo centrado, Figura 7. No entanto, os difratogramas também apresentam picos difratados por outras fases. As posições dos ângulos de difração $2 \theta$ dos picos identificados foram consistentes com as fichas cristalográficas CIF [9] dos carbonetos indicados na Tabela 3. Percebe-se que houve uma tendência à formação de compostos cúbicos, seja nos revestimentos formados por um ou dois elementos formadores de carboneto (titânio, cromo ou nióbio). No revestimento Ti confirma-se a formação do carboneto TiC. Nos revestimentos $\mathrm{Ti}-\mathrm{Cr}$ e $\mathrm{Ti}-\mathrm{Nb}$ foram identificados carbonetos "mistos", onde ambos os principais formadores encontram-se em solução sólida substitucional. As estruturas encontradas correspondem ao $\left(\mathrm{Ti}_{0,8}\right.$ $\left.\mathrm{Cr}_{0,2}\right) \mathrm{C}$ e ao ( $\left.\mathrm{Ti} \mathrm{Nb}\right) \mathrm{C}_{2}$, ambos cúbicos. A baixa intensidade difratada pela cementita $\mathrm{Fe}_{3} \mathrm{C}$ foi atribuída a baixa fração volumétrica deste composto nas amostras analisadas e pode sugerir que o carbono adicionado durante a produção das varetas Ti, Ti-Cr e Ti-Nb foi suficiente para a formação dos carbonetos ricos em titânio. 


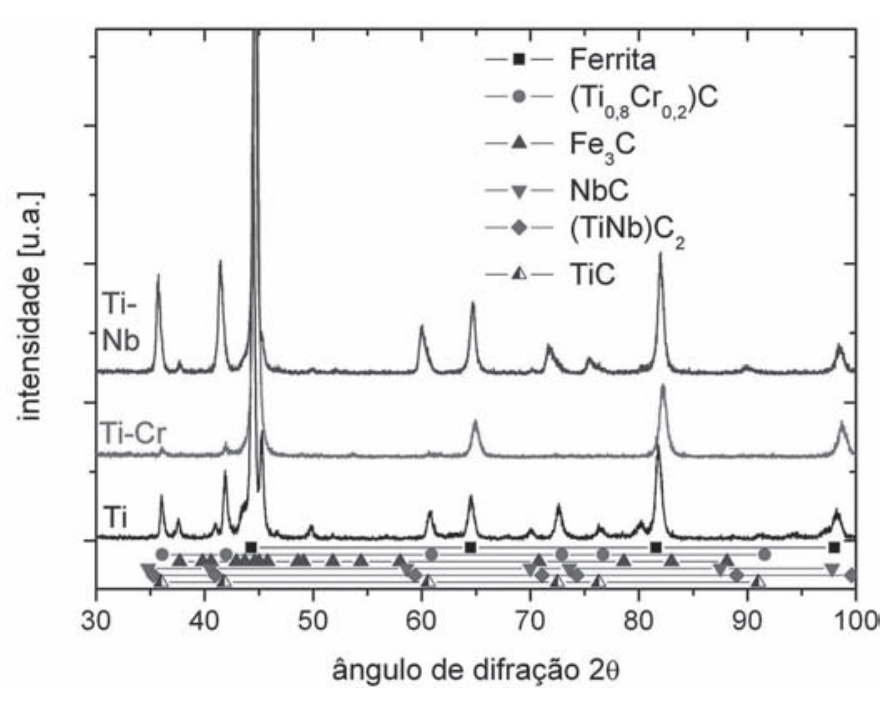

Figura 7. Difração de raios-X dos revestimentos Ti, Ti-Cr e $\mathrm{Ti}-\mathrm{Nb}$.

Tabela 3. Parâmetros cristalográficos das fases encontradas por difração de raios-X [9].

\begin{tabular}{|c|c|c|c|c|c|}
\hline \multirow{2}{*}{ fase } & ficha & \multirow{2}{*}{$\begin{array}{c}\text { estrutura } \\
\text { ICSD }\end{array}$} & \multicolumn{3}{|c|}{ parâmetro de rede $[\AA]$} \\
\cline { 5 - 6 } & IS. & a & b & c \\
\hline ferrita & 64795 & CCC (229) & 2,866 & - & - \\
\hline $\mathrm{TiC}$ & 44494 & CFC (225) & 4,318 & - & - \\
\hline$\left(\mathrm{Ti}_{0,8} \mathrm{Cr}_{0,2}\right) \mathrm{C}$ & 53106 & CFC (225) & 4,299 & - & - \\
\hline$(\mathrm{Ti} \mathrm{Nb}) \mathrm{C}_{2}$ & 77219 & CFC (225) & 4,396 & - & - \\
\hline $\mathrm{Fe}_{3} \mathrm{C}$ & 38308 & ORT (62) & 5,092 & 6,741 & 4,527 \\
\hline $\mathrm{NbC}$ & 159872 & CFC (225) & 4,454 & - & - \\
\hline
\end{tabular}

Nota: S.G. corresponde ao grupo espacial da fase ou microconstituinte.

No aspecto qualitativo especula-se que as partículas morfologicamente grandes e não excessivamente facetadas seriam mais indicadas para compor um revestimento resistente à abrasão, pois a distribuição de tensões durante o desgaste seria melhor distribuída [17,18]. A fragmentação dos carbonetos pode ocorrer durante o desgaste, fazendo com que estas atuem como partículas abrasivas em movimento. Os carbonetos primários encontrados nas amostras crescem com facilidade no interior dos bolsões interdendríticos, resultando muitas vezes em cristais com centenas de micrometros de comprimento. A orientação do eixo de crescimento destes carbonetos é afetada pelo processo de soldagem, de forma que uma parcela dessas partículas tenha o seu eixo de crescimento numa orientação quase paralela à superfície do revestimento. Neste caso, as partículas teriam menor interação com a matriz, que dela se desacoplariam com maior facilidade e acelerariam o processo de desgaste. O crescimento dendrítico pode resultar numa distribuição irregular dos carbonetos ao longo da superfície, levando a um comportamento anisotrópico do revestimento em relação à resistência ao desgaste abrasivo que será investigado em estudos futuros.

\section{Conclusões}

Os revestimentos duros $\mathrm{Ti}$, $\mathrm{Ti}-\mathrm{Cr}$ e $\mathrm{Ti}-\mathrm{Nb}$ foram produzidos durante a soldagem por GTAW/TIG.

A fusão dos consumíveis preparados a partir da mistura de cavacos de titânio ASTM F67 com grafite (Ti), além das misturas feitas com ferro-ligas (Fe-Cr e Fe-Nb), permitiu a formação de partículas com morfologia dendrítica no metal de solda.

A difração de raios-X identificou estas partículas como carbonetos de titânio cúbicos com estequiometrias TiC, $\left(\mathrm{Ti}_{0,8} \mathrm{Cr}_{0,2}\right) \mathrm{C}$ e $(\mathrm{TiNb}) \mathrm{C}_{2}$, dependendo dos formadores de carboneto presentes no consumível.

A presença dos carbonetos promoveu aumento na dureza do metal de solda dos revestimentos analisados, que foi maior no revestimento $\mathrm{Ti}\left(490 \mathrm{HV}_{30}\right)$ e menor no revestimento $\mathrm{Ti}-\mathrm{Cr}$ (345 $\left.\mathrm{HV}_{30}\right)$.

O endurecimento dos revestimentos acompanhou o aumento da proporção dos elementos formadores de carbonetos na composição das varetas usadas na soldagem, que variou de 77,1\% em massa para o revestimento Ti-Cr para 99,0\% em massa no revestimento Ti.

\section{Agradecimentos}

Os autores agradecem ao Laboratório de Caracterização Estrutural do DEMa/UFSCar pelo apoio na caracterização microestrutural, à Implalife Biotecnologia, à CBMM e COFEL pelos insumos (cavacos e ferro-ligas) e as bolsas concedidas pelo CNPq (J.G.F.J. e J.G.) durante o desenvolvimento deste trabalho.

\section{Referências}

[1] LUTJERING, G.; WILLIAMS, J. C. Titanium. SpringerVerlag Berlin, Heidelberg, pp. 345-349, 2003.

[2] BUCHANAN, V. F.; SHIPWAY, P. H.; MCCARTNEY, D. G. Microstructure and abrasive wear behaviour of shielded metal arc welding hardfacings used in the sugarcane industry. Wear, v. 263, pp. 99-110, 2007.

[3] BERNS, H.; FISCHER, A. Microstructure of Fe-Cr-C Hardfacing Alloys with Additions of Nb, Ti and, B. Materials Characterization, v. 39, pp. 499-527, 1997.

[4] SABET, H.; KHIERANDISH, S.; MIRDAMADI, S.; M. GOODARZI. The Microstructure and Abrasive Wear Resistance of $\mathrm{Fe}-\mathrm{Cr}-\mathrm{C}$ Hardfacing Alloys with the Composition of Hypoeutectic, Eutectic and Hypereutectic. Tribology Letters, v. 44, pp. 237-245, 2011.

[5] LIMA, A. C., FERRARESI, V. A. Análise da Resistência ao Desgaste de Revestimento Duro Aplicado por Soldagem em Facas Picadoras de Cana-De-Açúcar. Soldagem e Inspeção, São Paulo, v. 15, n. 2, pp. 94-102, 2010.

[6] LIMA, A. C., FERRARESI, V. A. Análise da Microestrutura e da Resistência ao Desgaste de Revestimento Duro Utilizado pela Indústria Sucroalcooleira. Soldagem e Inspeção, São Paulo, v. 14, n. 2, pp. 140-150, 2009.

[7] BUCHELY, M.F.; GUTIERREZ, J. C.; LEÓN, L. M.; TORO, A. The effect of microstructure on abrasive wear of hardfacing 
alloys. Wear, v. 259, pp. 52-61, 2005.

[8] CORREA, E. O.; ALCÂNTARA, N. G.; TECCO, D. G.; KUMAR, R. V. The Relationship between the Microstructure and Abrasive Resistance of a Hardfacing Alloy in the Fe-Cr-CNb-V System. Metallurgical and Materials Transactions A, v. 38A, pp. 1671-1680, 2007.

[9] INORGANIC CRYSTAL STRUCTURE DATABASE (ICSD). Arquivos cristalográficos no formato CIF (Crystallographic Information Framework) disponíveis em http://www.fiz-karlsruhe.de/icsd.html . Acesso em Julho de 2013.

[10] AMERICAN SOCIETY FOR TESTING AND MATERIALS. E92: Standard Test Method for Vickers Hardness of Metallic Materials. West Conshohocken, 2003. 9 p.

[11] SHATYNSKI, S. R. The Thermochemistry of Transition Metal Carbides. Oxidation of Metals, v. 13 (2), pp. 105-118, 1979.

[12] YEDONG, H., ZHENGWEI, L., HUIBIN, Q., GAO, W. Standard Free Energy Change of Formation per Unit Volume: A New Parameter for Evaluating Nucleation and Growth of Oxides, Sulphides, Carbides and Nitrides. Material Research Innovations, v. 1 (3), pp. 157-160, 1997.

[13] COLTTERS, R. G. Thermodynamics of Binary Metallic Carbides: a Review. Materials Science and Engineering, v. 76, pp. 1-50, 1985.

[14] WANG, X. H.; ZOU, Z. D.; QU, S. Y.; SONG, S. L. Microstructure and wear properties of Fe-based hardfacing coating reinforced by $\mathrm{TiC}$ particles. Journal of Materials Processing Technology, v. 168, pp. 89-94, 2005.

[15] GOODHEW, P. J., HUMPHREYS, J., BEANLAND, R. Electron Microscopy and Microanalysis. $3^{\text {rd }}$ edition. London: Taylor \& Francis Inc, 2001. 251 p.

[16] WU, X.; XING, J.; FU, H.; ZHI, X. Effect of titanium on the morphology of primary $\mathrm{M}_{7} \mathrm{C}_{3}$ carbides in hypereutectic high chromium white iron. Materials Science and Engineering A, v. 457, p.180-185, 2007.

[17] YAER, X.; SHIMIZU K., MATSUMOTO H., KITSUDO T.; MOMONO T. Erosive wear characteristics of spheroidal carbides cast iron. Wear, v. 264, pp. 947 - 957, 2008.

[18] ZUM GAHR, K.-H. Microstructure and Wear of Materials. Tribology Series, volume 10, 1987. 559 p. 